\title{
Short-term outcomes between laparoscopy-assisted and open colorectomy for colorectal cancer in elderly patients: A case-matched control study
}

\author{
ZEXIAN CHEN $^{1 *}$, XIAOSHENG HE ${ }^{1 *}$, JUANNI HUANG $^{2}$, YIKE ZENG $^{3}$, \\ LEI LIAN ${ }^{1}$, XIAOJIAN WU ${ }^{1}$, JIAN LEI ${ }^{3}$, JIANPING WANG ${ }^{1}$ and PING LAN ${ }^{1}$ \\ ${ }^{1}$ Department of Colorectal Surgery, The Sixth Affiliated Hospital, Sun Yat-Sen University; \\ Departments of ${ }^{2}$ Geriatrics and ${ }^{3}$ Gastrointestinal Surgery, The First Affiliated Hospital, \\ Guangzhou Medical University, Guangzhou, Guangdong 510655, P.R. China
}

Received January 8,2015; Accepted May 27, 2015

DOI: $10.3892 / \mathrm{mco} .2015 .585$

\begin{abstract}
With the increase in life expectancy, surgical intervention for colorectal cancer (CRC) is more frequently performed in elderly patients. This retrospective study was designed to compare short-term outcomes between laparoscopy-assisted colorectomy (LC) and open colorectomy (OC) in elderly patients with CRC. A total of 89 CRC patients aged $\geq 75$ years undergoing $L C$ were matched with 89 counterparts undergoing OC. The matching criteria included general information and preoperative status. The operative data and short-term postoperative outcomes were compared. Following analysis, patients in the LC and OC groups were comparable for the matching criteria. Compared with the OC group, the operative time was longer $(\mathrm{P}=0.046)$, but the estimated blood loss $(\mathrm{P}<0.001)$ and intraoperative transfusion $(\mathrm{P}=0.042)$ were less in the LC group. As regards short-term postoperative outcomes, the duration of postoperative hospital stay was shorter $(\mathrm{P}=0.001)$ and the incidence of wound complications was lower $(\mathrm{P}=0.044)$ with $\mathrm{LC}$. The overall complication, other complications, reoperation and mortality rates were comparable between the two groups. In conclusion, considering the operative variables and short-term outcomes, LC is a safe procedure and appears to be superior to OC for elderly patients with CRC.
\end{abstract}

Correspondence to: Dr Ping Lan, Department of Colorectal Surgery, The Sixth Affiliated Hospital, Sun Yat-Sen University, 26 Yuancun Erheng Road, Guangzhou, Guangdong 510655, P.R. China

E-mail: sumslp@163.com

*Contributed equally

Key words: laparoscopy-assisted colorectomy, open colorectomy, short-term complications, elderly patients, colorectal cancer

\section{Introduction}

Due to the significant advances in life quality and health care, life expectancy continues to increase worldwide, with a consequent increase in the elderly population. The incidence of colorectal diseases necessitating surgical intervention, particularly colorectal cancer (CRC), usually increases with advancing age. In fact, approximately one half of patients with CRC are aged $>70$ years and CRC is the second leading cause of cancer-related mortality in this age group $(1,2)$. Aging per se, regardless of other factors, is not a prognostic factor in gastrointestinal surgery (3). However, advanced age is usually accompanied by underlying comorbidities, such as cardiovascular and pulmonary diseases, which may significantly affect the outcomes of surgical treatment for CRC. Thus, surgery for elderly CRC patients is a major medical care issue.

Surgeons usually select colorectomy for CRC treatment in resectable cases, which may be performed as open colorectomy (OC) or laparoscopy-assisted colorectomy (LC). The laparoscopic procedure, compared with laparotomy, is considered to be a safe and feasible procedure, associated with a milder immunological and inflammatory response (4). Furthermore, LC is reportedly associated with decreased morbidity and mortality, faster recovery and shorter hospital stay $(5,6)$. However, LC usually requires longer operative time and results in specific physiological changes affecting the cardiovascular and pulmonary systems (7). Due to these concerns and underlying comorbidities in elderly patients, surgeons face a dilemma when considering LC for CRC.

The availability of recent reports comparing $\mathrm{LC}$ and OC for elderly patients is limited (8-12), with data on CRC being even more scarse (12). To the best of our knowledge, no data contraposing LC and OC in the Chinese population are available. Therefore, we conducted this study to compare the short-term outcomes of LC and OC for elderly CRC patients.

\section{Patients and methods}

Patient selection. Patients aged $\geq 75$ years undergoing elective LC for CRC between 2007 and 2013 at the Sixth Affiliated 
Table I. Demographics and clinical characteristics of the patients.

\begin{tabular}{|c|c|c|c|}
\hline Variables & $\begin{array}{l}\text { LC group } \\
\quad(n=89)\end{array}$ & $\begin{array}{l}\text { OC group } \\
(n=89)\end{array}$ & P-value \\
\hline Age (years) & $78.6 \pm 3.1$ & $79.0 \pm 3.8$ & 0.375 \\
\hline Gender ratio, $\mathrm{F} / \mathrm{M}$ & $35 / 54$ & $40 / 49$ & 0.448 \\
\hline $\operatorname{BMI}\left(\mathrm{kg} / \mathrm{m}^{2}\right)$ & $22.5 \pm 3.6$ & $21.7 \pm 3.4$ & 0.143 \\
\hline Hemoglobin $(\mathrm{g} / \mathrm{l})$ & $113.3 \pm 24.9$ & $111.8 \pm 20.9$ & 0.409 \\
\hline Comorbidities & $50(56.2)$ & $48(53.9)$ & 0.763 \\
\hline Previous abdominal surgery & $11(12.4)$ & $11(12.4)$ & 1.000 \\
\hline ASA score, I/II/III/IV & $1 / 36 / 46 / 2$ & $0 / 32 / 52 / 4$ & 0.528 \\
\hline Tumor location, colon/rectum & $51 / 38$ & $52 / 37$ & 0.879 \\
\hline TNM stage, $1 / 2 / 3 / 4$ & $13 / 33 / 33 / 10$ & $12 / 34 / 30 / 12$ & 0.848 \\
\hline
\end{tabular}

LC, laparoscopy-assisted colorectomy; OC, open colorectomy; F, female; M, male; BMI, body mass index; ASA, American Society of Anesthesiology. Values are expressed as mean \pm standard deviation, or as number (percentage).

Hospital of Sun Yat-sen University and the First Affiliated Hospital of Guangzhou Medical University (Guangzhou, China), were included in this retrospective study and then matched with the same number of patients who underwent $\mathrm{OC}$ for CRC during the same period. Thus, all the eligible patients were divided into two groups, namely the LC and the OC groups. Data on the preoperative status, surgical variables and short-term postoperative outcomes were obtained by careful chart review.

The exclusion criteria for the two groups were uniform and included emergency cases, patients who had received neoadjuvant therapy and cases without resection of the colon or rectum. Of note, conversion of LC to OC was excluded in our study.

This study was approved by the Institutional Review Boards of the two participating hospitals.

Matching standards. Patients in the OC group were selected to match those in the LC group according to general information and preoperative status. The matching criteria included age, gender, body mass index (BMI), preoperative hemoglobin level, comorbid diseases, previous abdominal surgery, American Society of Anesthesiology (ASA) score and diagnosis. The comorbid diseases included cardiovascular, respiratory and renal diseases, hypertension and diabetes, which may affect the choice of procedure. Other comorbidities, such as benign prostatic hyperplasia and cataract, were not considered to be significant. Among the aforementioned variables, BMI and preoperative hemoglobin level were used to assess the nutritional status, while comorbidity factors were evaluated by comorbid disease, previous abdominal surgery and, particularly, ASA score. These matching standards were, to some extent, applied to avoid unnecessary bias and confounding, as this study mainly focused on the comparison of the two surgical procedures.

Comparison of $L C$ and $O C$. Our attention was focused on the surgical and postoperative evaluation. The surgical variables included type of procedure performed (LC or OC), operative time, estimated blood loss, intraoperative transfusion, location of resection and type of anastomosis configuration, if required. Short-term postoperative outcomes, such as intensive care unit (ICU) stay, duration of postoperative hospital stay, short-term complications, reoperation due to complications and mortality within 3 months postoperatively, were included.

Statistical analysis. Data were analyzed using the Statistical Package for Social Science software, version 16.0 (SPSS Inc., Chicago, IL, USA). For all variables, descriptive statistics were conducted, including means and standard deviations or medians and ranges for continuous factors, and frequencies for categorical factors. Student's t-tests or Wilcoxon rank-sum tests were used to compare continuous factors, whereas Chi-square or Fisher's exact probability tests were used for categorical variables. The differences were considered statistically significant when the two-sided P-values were $<0.05$.

\section{Results}

General information. In total, 178 patients were included in this study; 89 patients underwent LC for CRC (55 from the Sixth Affiliated Hospital of Sun Yat-sen University and 34 from the First Affiliated Hospital of Guangzhou Medical University). A further 89 patients were assigned to the OC group according to the matching criteria. The oldest patient was aged 90 years at the time of the operation. The mean age was 78.6 years in the LC group and 79.0 years in the OC group $(\mathrm{P}=0.375)$, while the gender ratio was similar between the two groups $(\mathrm{P}=0.448)$. The preoperative nutritional status was comparable between the two groups, with an average BIM of 22.5 and $21.7 \mathrm{~kg} / \mathrm{m}^{2}(\mathrm{P}=0.143)$, and an average hemoglobin concentration of 113.3 and $111.8 \mathrm{~g} / \mathrm{l}(\mathrm{P}=0.409)$ in the $\mathrm{LC}$ and OC groups, respectively. As regards preoperative comorbidity factors, 56.2 and $53.9 \%$ patients had comorbid diseases in the LC and OC groups, respectively $(\mathrm{P}=0.763)$, while $12.4 \%$ of the patients in both groups had undergone previous abdominal surgery $(\mathrm{P}=1.000)$. More than one half of the patients in the LC and OC groups (53.9 and 62.9\%, respectively) had and ASA score of 3 or 4 . Overall, the LC and OC groups were comparable for the matching criteria. The demographics 
Table II. Surgical variables.

\begin{tabular}{|c|c|c|c|}
\hline Variables & LC group & OC group & P-value \\
\hline Operative time (min) & $236.3 \pm 87.5$ & $212.0 \pm 65.1$ & $0.046^{\mathrm{a}}$ \\
\hline Estimated blood loss (ml) & $100.0(10-2,200)$ & $200.0(30-3,000)$ & $<0.001^{\mathrm{a}}$ \\
\hline Intraoperative transfusion & $16(18.0)$ & $29(32.6)$ & $0.042^{\mathrm{a}}$ \\
\hline Location of resection & & & 0.293 \\
\hline Right colectomy & $17(19.1)$ & $24(27.0)$ & \\
\hline Left colectomy & $7(7.9)$ & $11(12.4)$ & \\
\hline Sigmoid resection & $25(28.1)$ & $17(19.1)$ & \\
\hline Rectal resection & $40(44.9)$ & $37(41.6)$ & \\
\hline Use of anastomosis configuration & & & 0.103 \\
\hline No & $3(3.6)$ & $8(11.9)$ & \\
\hline Yes $^{\mathrm{a}}$ & $80(96.4)$ & $59(88.1)$ & 0.139 \\
\hline Anastomosis ring & $9(11.3)$ & $12(20.3)$ & \\
\hline Staple & $71(88.7)$ & $47(79.7)$ & \\
\hline
\end{tabular}

${ }^{a}$ Hand-sewn anastomoses were not taken into consideration. LC, laparoscopy-assisted colorectomy; OC, open colorectomy. Values are

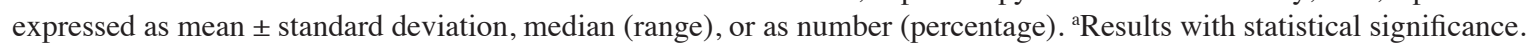

Table III. Postoperative evaluation.

\begin{tabular}{|c|c|c|c|}
\hline Variables & LC group & OC group & P-value \\
\hline ICU stay & $27(30.3)$ & $31(34.8 \%)$ & 0.522 \\
\hline Postoperative hospital stay duration (days) & $13.0(6-82)$ & $16.0(8-196)$ & $0.001^{\mathrm{a}}$ \\
\hline \multicolumn{4}{|l|}{ Complications } \\
\hline Overall & $29(32.6)$ & $37(43.8)$ & 0.214 \\
\hline Wound & $3(3.4)$ & $10(11.2)$ & $0.044^{\mathrm{a}}$ \\
\hline Abdominal infection & $2(2.2)$ & $6(6.7)$ & 0.278 \\
\hline Intestinal obstruction & $7(7.9)$ & $10(11.2)$ & 0.444 \\
\hline Anastomotic fistula & $3(3.4)$ & $3(3.4)$ & 1.000 \\
\hline Hernia & $1(1.1)$ & $2(2.2)$ & 1.000 \\
\hline Cardiovascular & $2(2.2)$ & $3(3.4)$ & 1.000 \\
\hline Respiratory & $7(7.9)$ & $13(14.6)$ & 0.154 \\
\hline Urinary infection & $3(3.4)$ & $3(3.4)$ & 1.000 \\
\hline Renal failure & $2(2.2)$ & $3(3.4)$ & 1.000 \\
\hline Stoma & $2(2.2)$ & $2(2.2)$ & 1.000 \\
\hline Reoperation for complications & $4(4.5)$ & $10(11.2)$ & 0.095 \\
\hline Mortality within 3 months & $2(2.2)$ & $5(5.6)$ & 0.441 \\
\hline
\end{tabular}

LC, laparoscopy-assisted colorectomy; OC, open colorectomy; ICU, intensive care unit. Values are expressed as mean \pm standard deviation, median (range), or as number (percentage). ${ }^{a}$ Results with statistical significance.

and clinical characteristics of the enrolled patients, with the P-values for matching are summarized in Table I.

Surgical variables. Laparoscopic surgery was 24 min longer compared with open laparotomy (236.3 vs. $212.0 \mathrm{~min}$, respectively; $\mathrm{P}=0.046$ ). In the LC group, the estimated blood loss was significantly lower compared to that in the OC group (100 vs. $200 \mathrm{ml}$, respectively; $\mathrm{P}<0.001$ ), as was the number of patients requiring intraoperative transfusion (18.0 vs. $32.6 \%$, respectively; $\mathrm{P}=0.042)$. The location of resection $(\mathrm{P}=0.293)$ and anastomosis appliance use were comparable between the two groups ( 96.4 vs. $88.1 \%, \mathrm{P}=0.103)$. The surgical variables are summarized in Table II.

Postoperative evaluation. The frequency of ICU stay was comparable between the two groups. The postoperative hospital stay duration (13.0 vs. 16.0 days, $\mathrm{P}=0.001)$ was significantly decreased in the LC group. The overall complication rates 
were $32.6 \%$ for $\mathrm{LC}$ and $43.8 \%$ for OC $(\mathrm{P}=0.214)$. However, wound complications, including wound infection and wound disruption occurred markedly more frequently in the OC group (3.4 vs. $11.2 \%, \mathrm{P}=0.044$ ). The incidence of complications other than wound complications was comparable between the LC and OC groups. A total of 14 patients (4 in the $\mathrm{LC}$ and 10 in the OC group, $\mathrm{P}=0.095$ ) required reoperation due to postoperative complications. The causes for reoperation included anastomotic fistula $(\mathrm{n}=1)$, intestinal obstruction $(\mathrm{n}=2)$, hernia $(n=2)$, stoma failure $(n=2)$ and secondary sutures for wound infection or disruption $(n=7)$. A total of 7 patients succumbed to postoperative multiple organ failure ( 2 in the LC and 5 in the $\mathrm{OC}$ group, $\mathrm{P}=0.441)$. The reoperation and mortality rates were similar between the two groups. The evaluation of postoperative outcomes is presented in Table III.

\section{Discussion}

The aim of this retrospective case-matched control study was to compare the short-term outcomes of LC and OC for elderly patients with CRC. We selected patients aged $\geq 75$ years, as this age is considered to exceed the normal life expectancy. In fact, the life expectancy in China is $\sim 75$ years (13). The preoperative status in the two groups was balanced by matching patients according to general information and clinical characteristics.

Following analysis, LC was found to be associated with a significantly lower estimated blood loss and intraoperative transfusion rate, although the operative time was longer when compared to laparotomy. These results are similar to those reported by previous studies, as the operative time of the laparoscopic procedure was reported to be 20-30 min longer compared to laparotomy (9-12). Only in the study by Senagore et al was the operative time reported to be shorter with LC (14), but no further discussion was offered regarding this finding. Despite the longer operative time, less blood loss and lower transfusion rate demonstrated that LC is safe for elderly patients.

Moreover, the postoperative hospital stay was significantly shorter in the LC group compared with that in the OC group. The decreased hospital stay reflects the faster postoperative recovery of oral intake of food, bowel function and physical activity $(9,10,15-18)$, athough such variables were not analyzed in our study.

As regards postoperative complications, we observed that wound complications, including wound infection and disruption, occurred significantly less frequently in the LC group. Stewart et al (19) and Frasson et al (8) reported similar results. This may be due to the incision in OC being longer and thus easier to develop complications.

Other complications, reoperation for complications and mortality, were not statistically significantly different between the two groups. According to the absolute numbers of occurrence, it appeared that, to some extent, $\mathrm{LC}$ was superior to OC. For example, the cases of abdominal infection, respiratory infection, reoperation for complications and mortality were 2 vs. 6,7 vs. 13,4 vs. 10 and 2 vs. 5 in the LC and OC groups, respectively. Generally, complications and mortality were comparable in previous studies as well, indicating that LC is at least as safe as OC for elderly patients.
Finally, there were certain limitations to the present study. First, the retrospective design of the study requires consideration, although it may be impractical and difficult to perform randomized controlled trials in elderly patients with CRC and, in order to avoid selection bias, patients in the two groups were matched for general information and preoperative status prior to the analysis. Future studies with larger sample sizes are required to confirm our results. Furthermore, this study only focused on short-term outcomes. For surgical intention, particularly for cancer, long-term outcomes, such as recurrence, metastasis and survival rate, should also be considered. Previously published meta-analyses (20-22) reported that long-term results, such as recurrence rate and 5-year survival rate, were similar between $\mathrm{LC}$ and $\mathrm{OC}$, but the analyses were not specific to elderly patients. As our follow-up of the patients was insufficient to assess long-term effects, this issue should be addressed in the future.

Considering the operative variables and short-term outcomes, $\mathrm{LC}$ is a safe and even superior procedure to $\mathrm{OC}$ for elderly patients with CRC. However, further studies including more patients are required to confirm these results and assess long-term outcome.

\section{Acknowledgements}

This study was supported by grants from the ' 985 project' of Sun Yat-Sen University and Guangdong Translational Medicine Public Platform (no. 4202037) and the National Natural Science Foundation of China (no. 81072046).

\section{References}

1. Levi F, Lucchini F, Negri E, Boyle P and La Vecchia C: Changed trends of cancer mortality in the elderly. Ann Oncol 12: 1467-1477, 2001.

2. Folprecht G, Cunningham D, Ross P, et al: Efficacy of 5-fluorouracil-based chemotherapy in elderly patients with metastatic colorectal cancer: a pooled analysis of clinical trials. Ann Oncol 15: 1330-1338, 2004.

3. Tan KY, Konishi F, Kawamura YJ, et al: Laparoscopic colorectal surgery in elderly patients: a case-control study of 15 years of experience. Am J Surg 201: 531-536, 2011.

4. Sylla P, Kirman I and Whelan RL: Immunological advantages of advanced laparoscopy. Surg Clin North Am 85: 1-18, 2005.

5. Kang CY, Chaudhry OO, Halabi WJ, et al: Outcomes of laparoscopic colorectal surgery: data from the Nationwide Inpatient Sample 2009. Am J Surg 204: 952-957, 2012.

6. Orcutt ST, Marshall CL, Robinson CN, et al: Minimally invasive surgery in colon cancer patients leads to improved short-term outcomes and excellent oncologic results. Am J Surg 202: 528-531, 2011.

7. Abraham NS, Young JM and Solomon MJ: Meta-analysis of short-term outcomes after laparoscopic resection for colorectal cancer. Br J Surg 91: 1111-1124, 2004.

8. Frasson M, Braga M, Vignali A, Zuliani W and Di Carlo V: Benefits of laparoscopic colorectal resection are more pronounced in elderly patients. Dis Colon Rectum 51: 296-300, 2008.

9. Lian L, Kalady M, Geisler D and Kiran RP: Laparoscopic colectomy is safe and leads to a significantly shorter hospital stay for octogenarians. Surg Endosc 24: 2039-2043, 2010.

10. Pinto RA, Ruiz D, Edden Y, Weiss EG, Nogueras JJ and Wexner SD: How reliable is laparoscopic colorectal surgery compared with laparotomy for octogenarians? Surg Endosc 25: 2692-2698, 2011

11. Fernandes R, Shaikh I and Doughan S: Outcomes of elective laparoscopic colorectal operations in octogenarians at a district general hospital in South East England. World J Gastrointest Surg 5: 9-11, 2013. 
12. Issa N, Grassi C, Melki Y, Powsner E and Dreznik Z: Laparoscopic colectomy for carcinoma of the colon in octogenarians. J Gastrointest Surg 15: 2011-2015, 2011.

13. Yang G, Wang Y,Zeng Y, et al: Rapid health transition in China, 1990-2010: findings from the Global Burden of Disease Study 2010. Lancet 381: 1987-2015, 2013.

14. Senagore AJ, Madbouly KM, Fazio VW, Duepree HJ, Brady KM and Delaney CP: Advantages of laparoscopic colectomy in older patients. Arch Surg 138: 252-256, 2003.

15. Feng B, Zheng MH, Mao ZH, et al: Clinical advantages of laparoscopic colorectal cancer surgery in the elderly. Aging Clin Exp Res 18: 191-195, 2006

16. Vignali A, Di Palo S, Tamburini A, Radaelli G, Orsenigo E and Staudacher C: Laparoscopic vs. open colectomies in octogenarians: a case-matched control study. Dis Colon Rectum 48: 2070-2075, 2005.

17. Delgado S, Lacy AM, García Valdecasas JC, et al: Could age be an indication for laparoscopic colectomy in colorectal cancer? Surg Endosc 14: 22-26, 2000.
18. Kapritsou M, Korkolis DP and Konstantinou EA: Open or laparoscopic surgery for colorectal cancer: a retrospective comparative study. Gastroenterol Nurs 36: 37-41, 2013.

19. Stewart BT, Stitz RW and Lumley JW: Laparoscopically assisted colorectal surgery in the elderly. Br J Surg 86: 938-941, 1999.

20. Kuhry E, Schwenk WF, Gaupset R, Romild U and Bonjer HJ: Long-term results of laparoscopic colorectal cancer resection. Cochrane Database Syst Rev 16: CD003432, 2008.

21. Ohtani H, Tamamori Y, Arimoto Y, Nishiguchi Y, Maeda K and Hirakawa K: A meta-analysis of the short- and long-term results of randomized controlled trials that compared laparoscopy-assisted and open colectomy for colon cancer. J Cancer 3: 49-57, 2012.

22. Di B, Li Y, Wei K, et al: Laparoscopic versus open surgery for colon cancer: A meta-analysis of 5-year follow-up outcomes. Surg Oncol 22: e39-e43, 2013. 